\title{
Practical long-term planning in narrow vein mines - a case study
}

MM Khani Mandalay Resources Costerfield Operations, Australia

\begin{abstract}
A reliable long-term plan is essential in achieving economic success in a narrow vein mining operation. The plan must include significant items such as an appropriate and safe design concept, geology and geotechnical considerations, adequate ground support systems, development and production resources' capacity and their limitations, required infrastructure and all associated costs. In this paper, a practical long-term plan and schedule for an underground mine located at Costerfield in Victoria is presented, discussing all main areas of concern regarding narrow vein mining. Enhanced production scheduler (EPS) software is the current tool that is used for long-term planning and production scheduling at this mine. A comparison between EPS and Excel (the past tool for scheduling) is presented. Also, a comparison between forecast and actual production is presented illustrating good alignment between the two.
\end{abstract}

\section{$1 \quad$ Introduction}

Long-term mine planning and production scheduling aim to define the best or optimal mine plan subject to the constraints imposed by physical and geological conditions, budget deliverables and the operational mining approach. The term 'best' is defined by management objectives. These typically include maximising the monetary value of the mining project as well as guaranteeing a safe operation. Eventually, the best plan should meet the budget and shipment targets and ensure safe operations. Defining a production sequence that meets these tight production targets is a complex and multi-dimensional task. Multiple different types of ore including low, medium and high grade ore from different veins and different working faces have to be blended to produce the anticipated product.

In this case study, a practical long-term mine plan as well as a production scheduling process is presented for an underground antimony-gold mine located at Costerfield in Victoria, Australia. This operation is a property owned and operated by Mandalay Resources Corporation. The whole planning process comprises of a few stages: (a) block model manipulation; (b) life-of-mine (LOM) design; and (c) production scheduling. The (a) and (b) stages are completed using Studio 5D Planner (S5D) and stage (c) is completed using EPS. Both software products are produced by Datamine. During production scheduling all other operational requirements, such as required infrastructures (electrical, ventilation, dewatering) and resources, are considered.

In the past, Mandalay used only Microsoft Excel as the tool for planning, which had some significant issues for the planning and production scheduling.

\section{Project description}

The Costerfield Mine incorporating the Augusta Lodes and Cuffley Lode is an underground antimony-gold mine currently producing approximately $150 \mathrm{ktpa}$ of mill feed from a variety of mining methods to a depth of over $300 \mathrm{~m}$ below surface. The main mining method in use at this mine is bottom-up longhole stoping (LHS) with cemented rockfill (CRF). Figure 1 illustrates a schematic diagram of the CRF stoping method. The mining sequence will follow a bottom-up sequence, mining from the northern and southern extents retreating toward the central access. This sequence enables a consistent production profile to be maintained as it allows for dual development headings on each level. Crown pillars are partly extracted 
using half upper stoping (HUS), which is blind uphole stoping after completing above and below stope blocks. Figure 2 shows a long section of current levels.

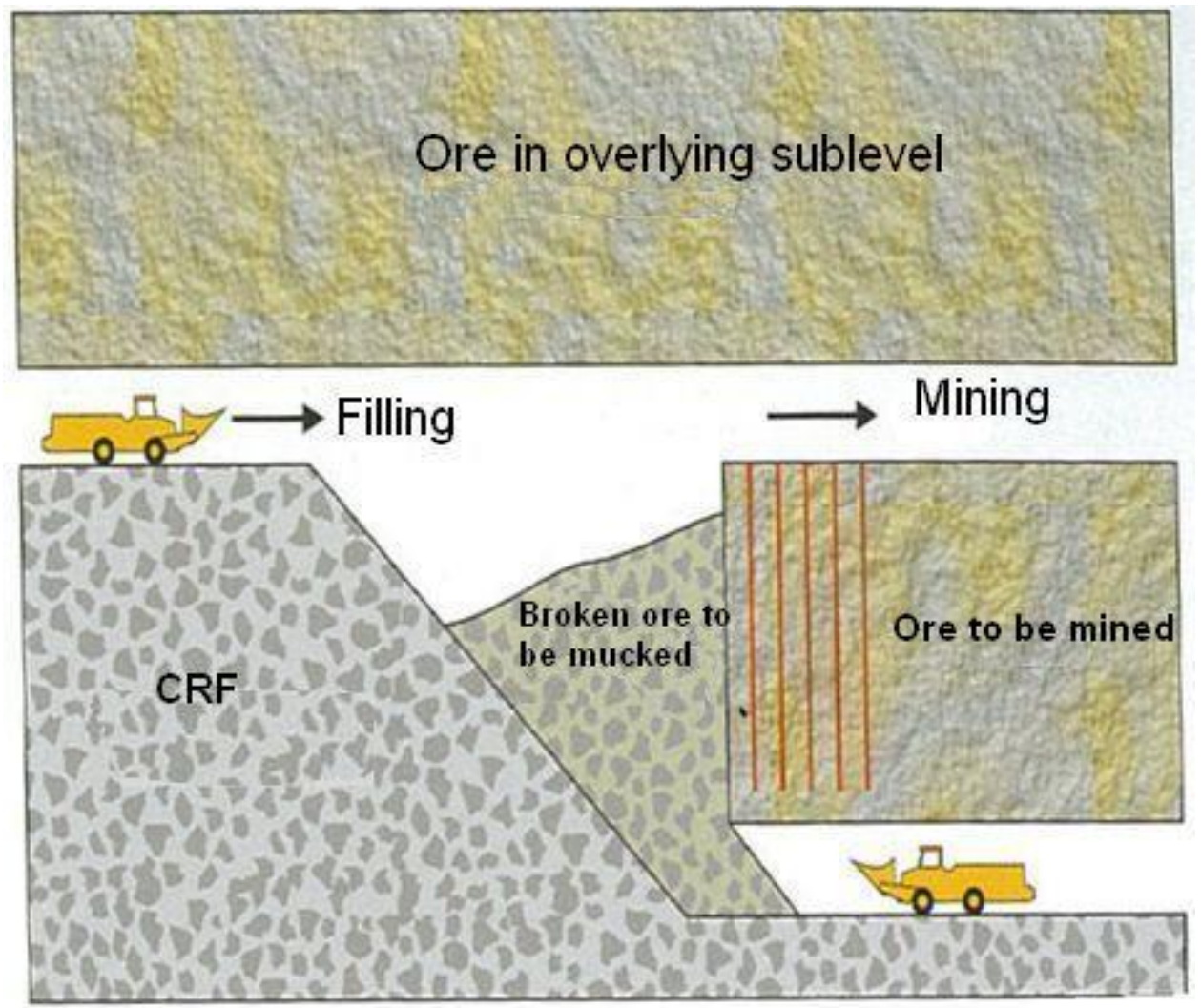

Figure 1 Longhole stoping method (Mandalay Resources 2012)

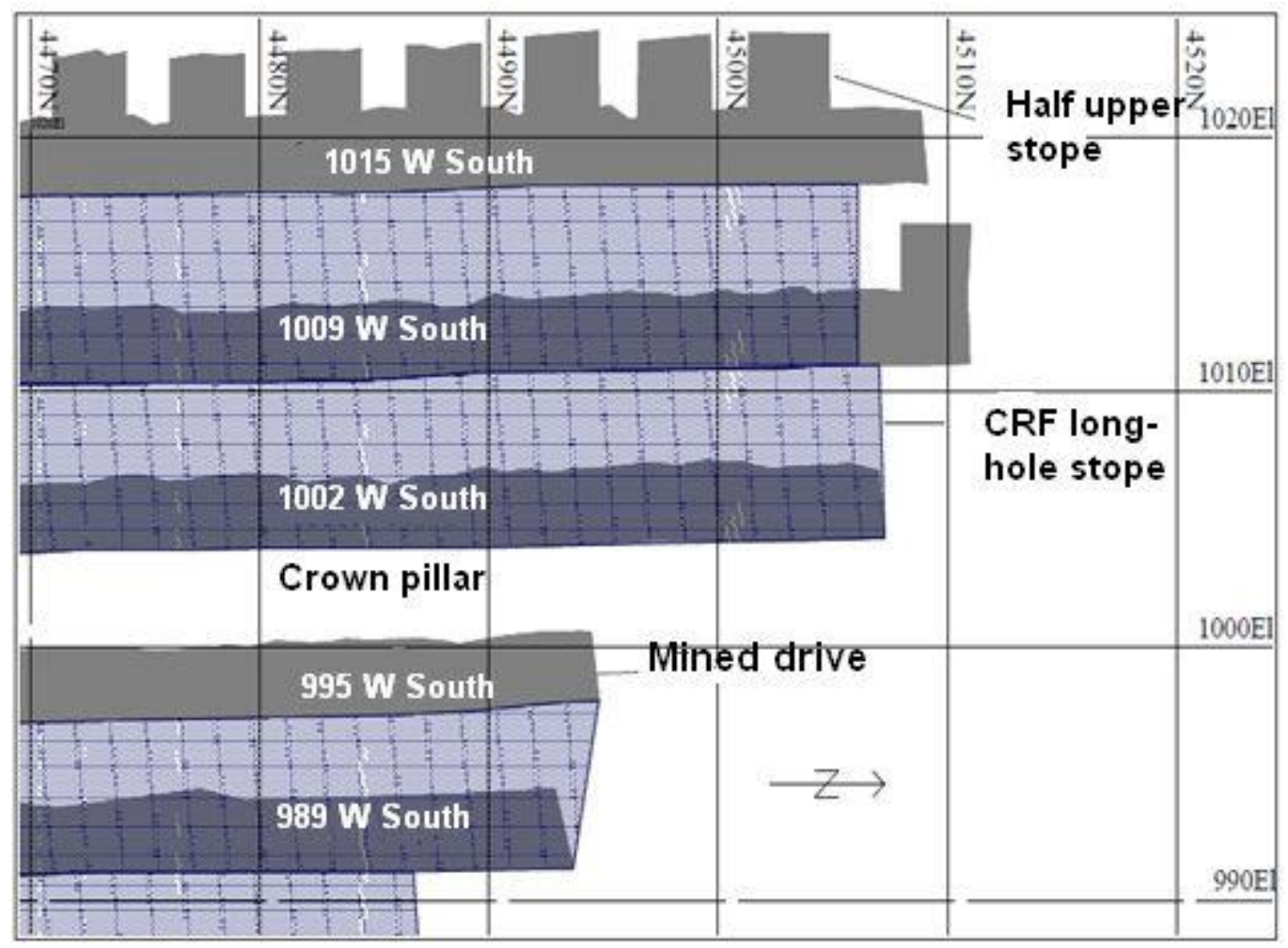

Figure 2 Long section of Augusta Mine stoping showing CRF stopes and crown pillar (Mandalay Resources 2012) 


\section{$3 \quad$ Mine design and planning process}

All mine design work has been completed using S5D Planner with all mine scheduling occurring in EPS.

The mining shapes designed in S5D Planner were assessed against the block model in order to calculate tonnes and grade. A 3D extended block model was used for the interrogation and mining depletion process of the designed mining shapes.

The mining schedule evaluated mining areas within the Augusta and Cuffley Mineral Resources above the gold equivalent cutoff grade.

After completing the interrogation and depletion process, dependency rules including schedule constraints were applied to the designed shapes to link all mining activities in a logical manner within the Studio 5D Planner project. This information was then exported to an EPS file for scheduling purposes.

The LOM design includes all capital and operating development as well as stoping areas.

Planned dilution was considered for both the designed ore drive development and stoping. Figure 3 shows a 3D view of the design. All major structures have been taken into account for the LOM design.

EPS was used for life of mine scheduling. The key assumptions such as cutoff grade, mining dilution and recovery factors, assigned resources and rate of mining were included in the scheduling calculations. Several scenarios were evaluated using EPS to ensure that the LOM design generated the highest possible net present value (NPV).

These design and scheduling programs are also in use for quarterly and monthly planning purposes.

The mine design parameters that have been used in the design of this mine are summarised in Table 1.

Table 1 Mine design parameters

\begin{tabular}{lcc}
\hline Description & \multicolumn{1}{c}{ Dimensions } & Gradient \\
\hline Decline & $4.8 \mathrm{mH} \times 4.5 \mathrm{~mW}$ & $1: 7$ down \\
Decline sumps & $4.8 \mathrm{mH} \times 4.5 \mathrm{~mW}$ & $1: 6$ down \\
\hline Stockpiles & $4.8 \mathrm{mH} \times 5.0 \mathrm{~mW}$ & $1: 50 \mathrm{up}$ \\
\hline Level crosscut & $4.8 \mathrm{mH} \times 5.0 \mathrm{~mW}$ & $1: 50 \mathrm{up}$ \\
\hline Truck tip & $6.5 \mathrm{mH} \times 5.0 \mathrm{~mW}$ & $1: 50 \mathrm{up}$ \\
\hline CRF mixing bay & $4.8 \mathrm{mH} \times 4.5 \mathrm{~mW}$ & $1: 10$ down \\
\hline Operating level access & $2.8 \mathrm{mH} \times 2.4 \mathrm{~mW}$ & $1: 7$ up; 1:7 down \\
\hline Production development (airleg) & $2.8 \mathrm{mH} \times 1.8 \mathrm{~mW}$ & $1: 50$ up \\
\hline Level spacing & $10.0 \mathrm{~m}$ & N/A \\
\hline
\end{tabular}




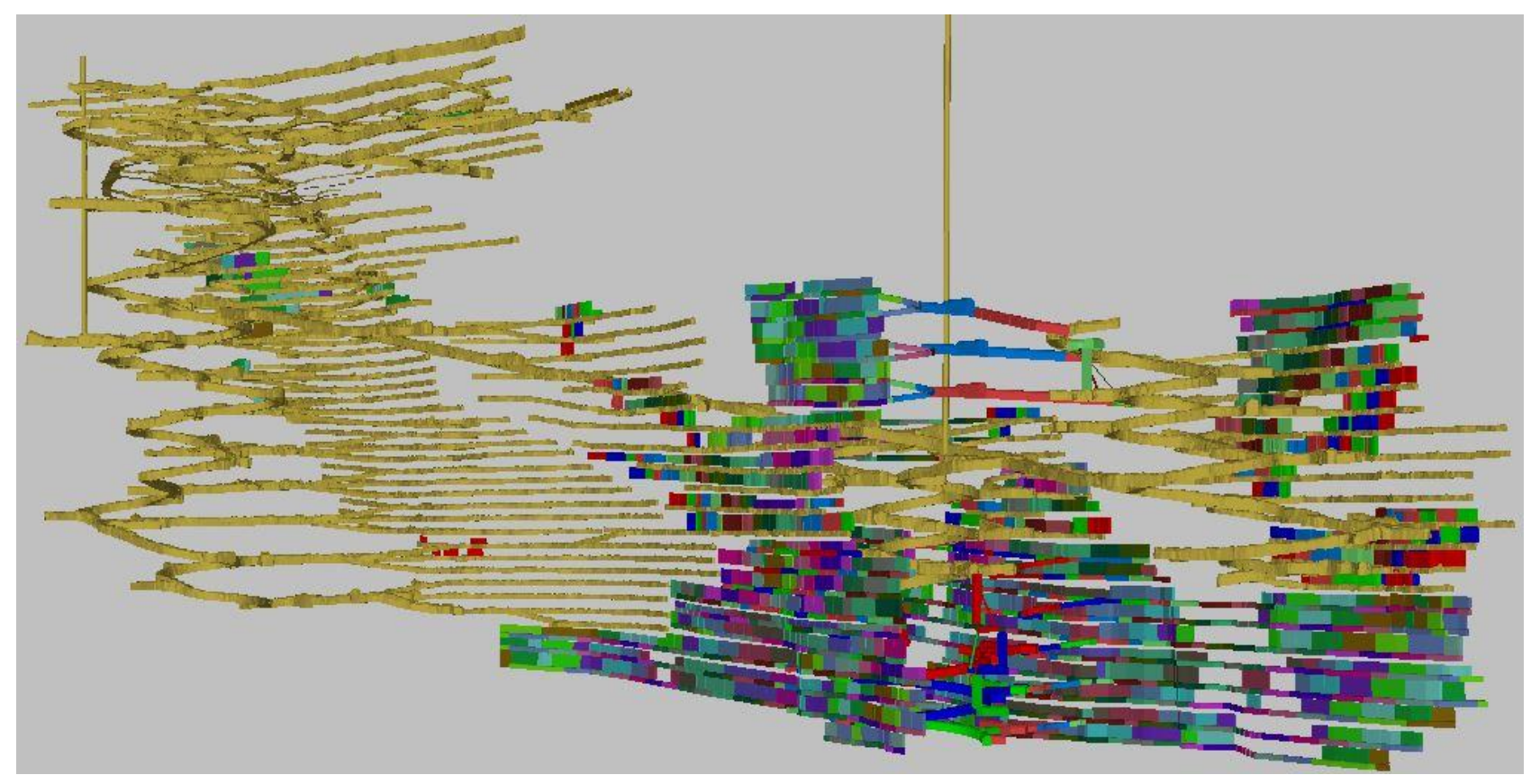

Figure 3 LOM design with existing as built

\subsection{Scheduling}

EPS was used for scheduling purposes. After completing and applying sequencing rules to the design elements, the LOM design was exported to EPS for scheduling. EPS has functionalities to show all activities in several ways and can be visualised in an integrated program named EPS InTouch.

Resources and their production rates were applied in EPS. Five types of resources were considered; one jumbo for capital development, a second resource for operating development, third resource is for stoping, fourth resource is for vertical rise development and the last resource is an escape way miner which covered all the possible development and production stages. Based on the number of available equipment and miners, the rate of mining for each resource was calculated. The scheduled resource rates are listed in Table 2.

\section{Table 2 Resources rates}

\begin{tabular}{ll}
\hline Resources & Rate \\
\hline Jumbo & $180-240 \mathrm{~m} /$ month \\
Operating development & $400-450 \mathrm{~m} /$ month \\
Stoping & $6,500-7,500$ tonnes/month \\
Vertical rise miner & $40 \mathrm{~m} /$ month \\
Escape way miner & $40 \mathrm{~m} /$ month \\
\hline
\end{tabular}

All required filters to make the scheduling more efficient were considered, such as cutoff grade, mining area, operating development, stoping tasks, completed tasks and so on.

\subsection{Cutoff grade}

Estimation of the design cutoff grade was based on past mining experience gained within the Augusta lodes as well as historical performances, both physical and economic, of the mining and processing methodologies. 
The distribution of grade over the measured and indicated Mineral Resources was considered to enable grade-tonnage curves to be generated from which cutoff equations were determined. Based on the historical cost estimates from the current Augusta Mine as well as the planned future cost structure for the $10 \mathrm{~m}$ level interval spacing CRF mining method, a cutoff grade of $5.0 \mathrm{~g} / \mathrm{t}$ AuEq was calculated and applied to the Mineral Resource to determine the mine design shapes (i.e. stope shapes) that possessed acceptable economic grade to warrant mining. After completion of the economic modelling, the break-even cutoff grade was reviewed and estimated to be between 4.5 and $5.0 \mathrm{~g} / \mathrm{t} \mathrm{AuEq}$.

A further iteration was completed to review stopes that were included based on cutoff grade that required significant additional development. As a result of this, some stoping areas were excluded from the Mineral Reserve in order to improve the NPV.

\subsection{Level development}

Production drive development is designed to be mined to ensure the ore is positioned in the face in order to minimise the hanging wall exposure. All production development is developed under geology control. Production drives are excavated and supported by handheld mining methods that have been proven to be generally stable and productive at the Augusta Mine.

\subsection{Vertical development}

Ventilation rises of $3.5 \times 3.5 \mathrm{~m}$ are designed to be excavated and supported between levels to extend the existing primary exhaust system both above and below the Cuffley exhaust shaft bottom. Ladder rising is used for the installation of escape ways in order to provide a reliable secondary means of egress.

\subsection{Stoping}

Stoping comprises mainly longitudinal longhole stoping in conjunction with CRF and crown half-uppers. Figure 2 is a long section of production drive development and stoping panels.

A default strike length of $10 \mathrm{~m}$ is assumed for all stopes. Material is assumed to have a swell factor of $30 \%$ and non-mineralised material is allocated a default relative density of $2.72 \mathrm{t} / \mathrm{m}^{3}$. The relative density of mineralised material is estimated within the resource model.

\subsection{Geotechnical plan}

A Q block model based on geotechnical data was prepared to estimate where additional ground support may be required for the stoping areas. Based on this information, two patterns of cable bolting were utilised which had been used within the mine with good results. The reason to add cable bolt drilling in the schedule was to ensure sufficient resources were available to undertake the drilling and cable bolt installation and also to determine the cost of installation, both of which influence the long-term mine plan.

\subsection{Infrastructure plan}

Infrastructures such as primary and secondary ventilation, submersible pumps, sumps, pump stations, substations, service holes and escape ways were all included in the LOM plan. Table 3 shows the 2015 required infrastructure. 
Table 3 LOM infrastructure plan

\begin{tabular}{|cccc}
\hline Date & Level & Description & $\begin{array}{c}\text { Electrical load } \\
(\mathbf{k w})\end{array}$ \\
\hline 1 April 2015 & 909 & Secondary fan & 110 \\
& 884 & Sump & 18 \\
1 1 May 2015 & 869 & Secondary fan & 110 \\
& 864 & Sump & 18 \\
\hline 1 June 2015 & 849 & Substation & - \\
\hline 1 July 2015 & 849 & Secondary fan & 110 \\
\hline 1 August 2015 & 844 & Pump Station & 110 \\
\hline & 1015 & Sump & 18 \\
\hline
\end{tabular}

Based on the infrastructural plan, a LOM electrical plan was prepared to illustrate all the required power for the LOM. This electrical plan ensured future resource and substation requirements were identified well before the infrastructure was required. Based on individual electrical load of all required electrical equipment for the LOM, a sheet was prepared, and is updated on a quarterly basis.

\subsection{Stockpile and rock waste management}

Based on the LOM plan, a waste rock and stockpile management strategy was defined and is updated on a monthly basis. The target for production is to achieve the budget metal on a quarterly basis; the target is updated monthly. According to every monthly plan, there is a plan for stockpile blending. Usually unplanned low grade mined ore is stockpiled in an area near the plant and will be blended from time to time during the periods when mining occurs in high grade areas. Stockpile management is controlled over a 3-month period and is updated on a monthly basis.

A rock waste management strategy was prepared based on the LOM plan which enables adequate management of the waste rock storage capacity available. The waste tonnage forecast is assessed against the actual trucked waste to the waste dump. The good agreement between forecast and actual waste in cumulative format is shown in Figure 4. This demonstrates that the forecast plan is achieved in this case with $85 \%$ accuracy (i.e. forecast is $85 \%$ of actual). 


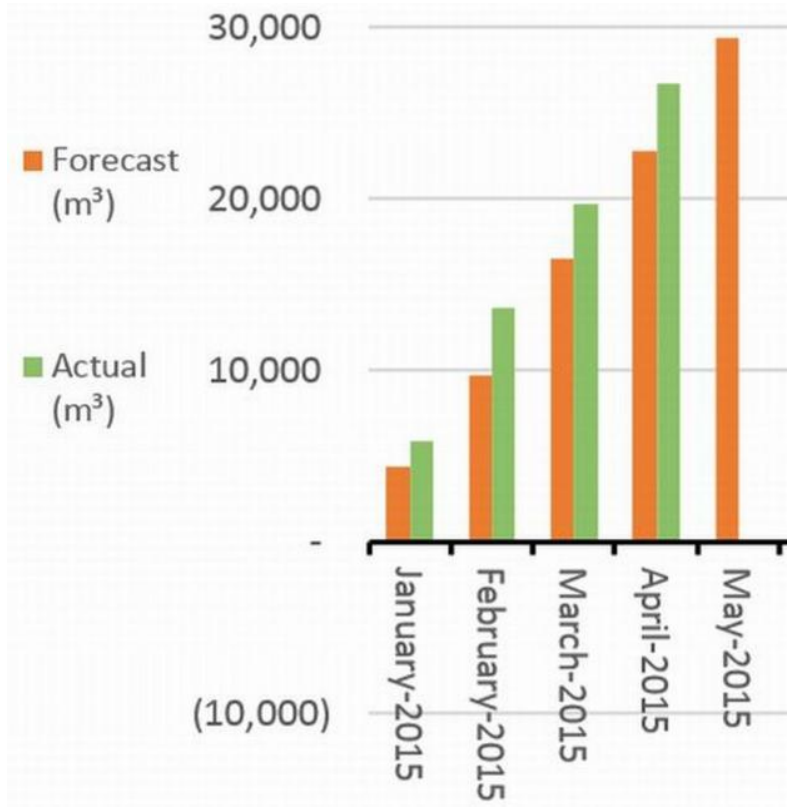

Figure 4 Actual versus forecast waste

\section{$4 \quad$ Actual against forecast}

End of month (EOM) reconciliation is undertaken as a tool to compare the production and development advance against forecast. In stoping, the strike area is measured and compared against the forecast planned strike area. As it can be seen from Figure 5, a good agreement between forecast and actual strike area, differences within $5 \%$, has been obtained over the last few months. In addition, a similar comparison is undertaken for capital and operating development, but using advanced metres as the measurement, which demonstrates the comparison each month.

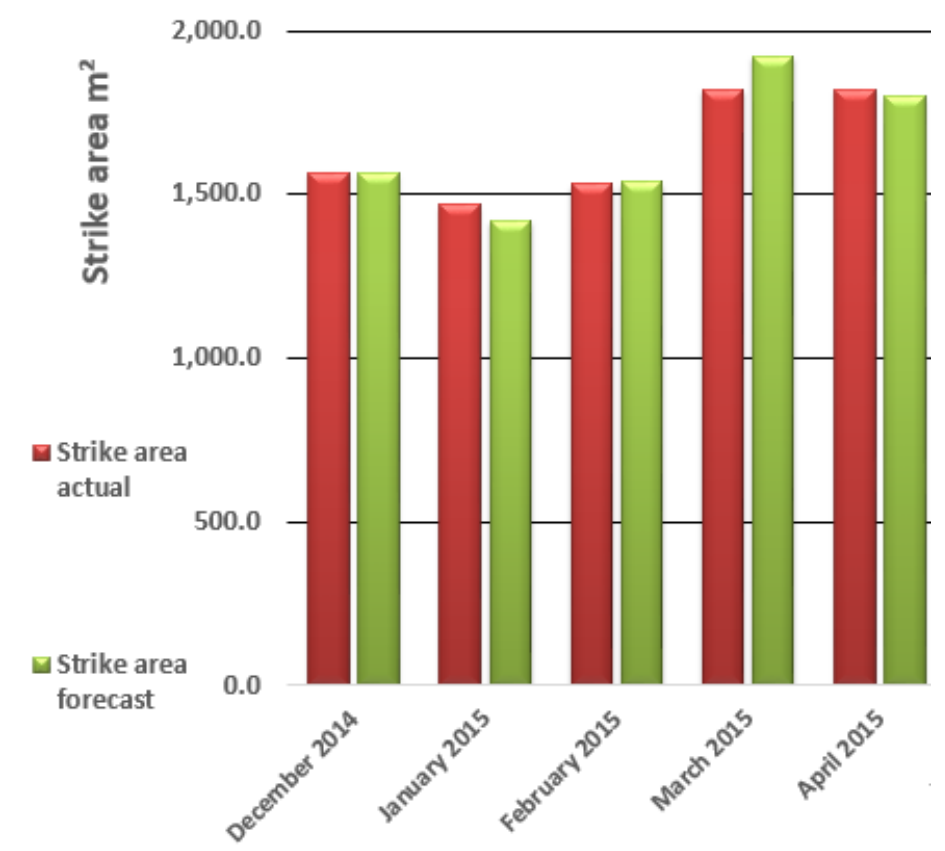

Figure 5 Actual versus forecast stoping strike area

As well as these comparisons, a final reconciliation is done to compare the actual produced mined tonnes against budget. This illustrates an almost $90 \%$ accuracy over 11 months (i.e. forecast is $90 \%$ of actual) and proves the forecast to this level of confidence. The graph in Figure 6 presents a comparison of the actual mined and budget as well as forecast tonnes. 


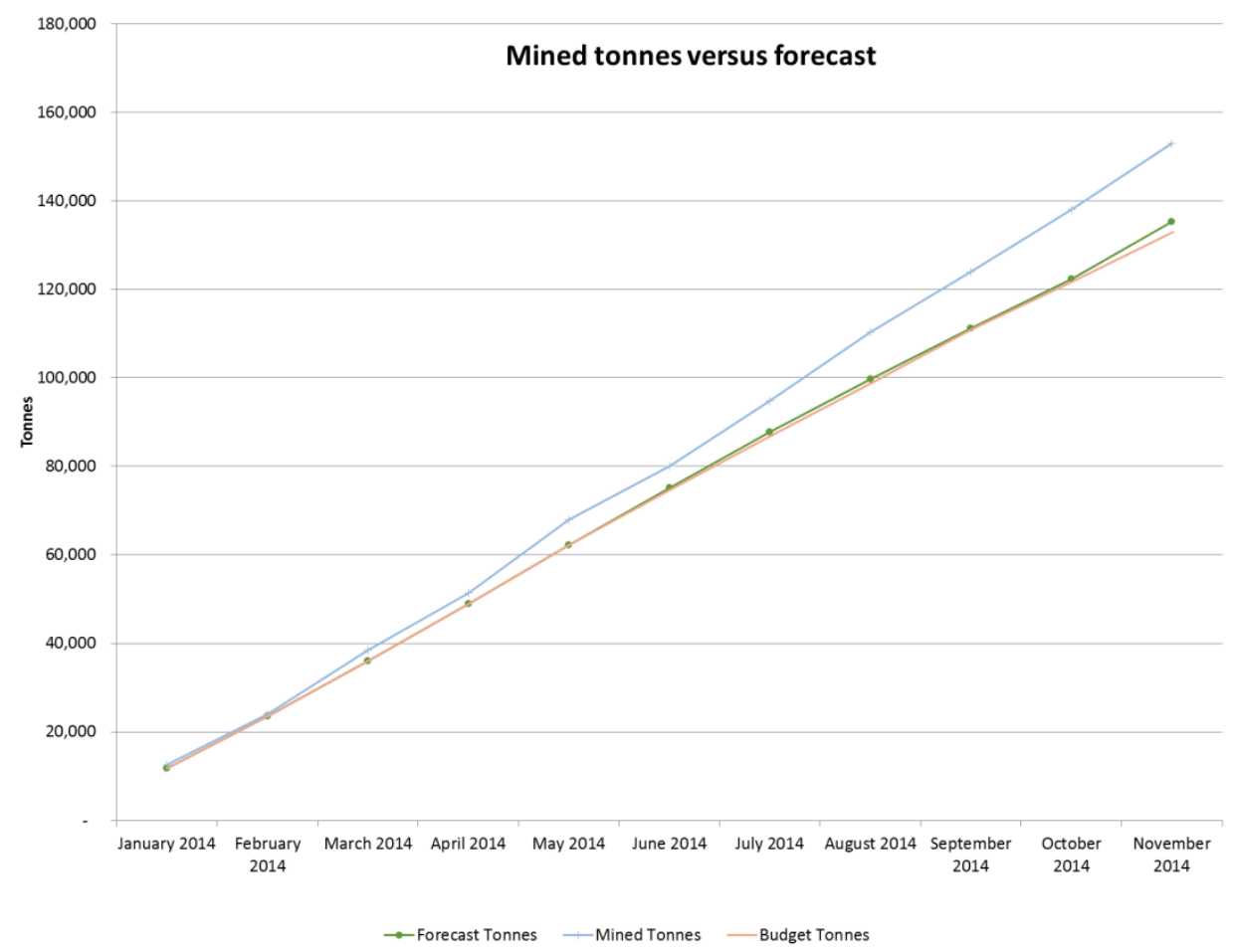

Figure 6 Total mined versus forecast mined tonnes

\section{Comparison of past and current tools}

As discussed above, in this case study, S5D and EPS were used as a long-term planning tool and there was agreement between what was planned to be mined and what was actually mined. It was determined that Excel was a good tool for reporting, but not for overall mine planning. Human error and controlling the linked and formulated sheets are some of the Excel issues for mine planning. Based on the reconciliation and comparison methodology that is described above, there was no good agreement between actual and forecast in the past. Also, there were issues with running different scenarios in a short period of time using Excel. Further, most of the planning topics presented in this paper were very difficult to undertake in Excel. Based on the experience gained at Costerfield, it is estimated that $65 \%$ accuracy is achieved for forecasts made using Excel as a long-term mining plan tool in this underground mine.

\section{Conclusion}

A practical long-term plan has been presented which showed proven reliability to achieve targets in a narrow vein mining operation. In this plan, all important planning items such as an appropriate and safe design concept, geology and geotechnical considerations, adequate ground support system, development and production resources' capacity and their limitations, required infrastructure and all associated costs were considered. S5D and EPS were used as the mine planning tools with significant benefits over Excel. The 85 to $95 \%$ accuracy of the new tools has been proven by good agreement of actual and forecast EOM reconciliation as well as budget targets.

\section{Acknowledgement}

The author acknowledges Mandalay Resource Costerfield Operations for its support and Shannon Green for his peer review of this paper.

\section{References}

Mandalay Resources 2012, Costerfield operations preliminary economic assessment, report, Mandalay Resources, Toronto, ON. 